\title{
Performance Evaluation and Responsibility Accounting
}

Field study: medical care institutions in north Jordan (NGOs and private sector)

\author{
Ibrahim Al-shomaly \\ Faculty of management \& finance \\ University of Jordan \\ E-mail: i.alshomaly@ju.edu.jo
}

Received: Dec. 11, 2012 Accepted: January 7, 2012 Published: January 8, 2013

doi:10.5296/jmr.v5i1.2856

URL: http://dx.doi.org/10.5296/jmr.v5i1.2856

\begin{abstract}
This study aims to disclose the methods that are used to evaluate the performance in the medical care sector in Jordan and the extent of their relation with the responsibility accounting principles. In order to achieve this goal, a questionnaire had been designed to obtain information of the sample which represents the medical institutions in the north of Jordan (NGOs and private sector). The study concluded that the medical institutions in northern Jordan are partially adopting the fundamentals of responsibility accounting system in the evaluation of its performance, but informally. This conclusion is supported by; First, The presence of definite organizational structures, where the centers (cost and profit centers) were divided according to those structures. Second, the absence of systematic preparation for budgets to each responsibility center. Third, the tendency toward decentralization(delegation of authority) in these institutions were weak, where there was significant influence by top management in the process of decision making and performance evaluation in centers and at the entire organization level.
\end{abstract}

Keywords: institutions, performance, accounting, NGOs (Non Government Organizations), budget. 


\section{Introduction}

Responsibility accounting is considered as an important control system and represents a source of information that facilitates decision making process in short and long ranges (Sarkar \& Yeshmen, 2005). As tool for evaluation, responsibility accounting system helps in measuring the divisions' performance in profit and nonprofit organizations alike, as mentioned by Malodia (2011). Corporations seek primarily to maximize their profits, while nonprofit organizations aim to offer free or low cost services for public as indicated by Moore (2003). Nevertheless, these organizations have goals in common, they are concentrating on the consumers satisfaction of the products rendered either they were goods or services, besides they also suffer of capital scarcity as an economic challenge, Consequently, Williams (1938) stated that capital should be managed efficiently. This efficiency could be achieved through implementation of responsibility accounting system. So, it assumed that this system may help in achieving the organization's financial and operational goals.

Garrison (2000) believed that the implementation of responsibility accounting system requires adoption of decentralization. By which, the organization is partitioned into units (also may be named subunits) as mentioned by Bogue (2000). Gordon (2004) considered that in each unit, it supposed to be its managers have all the capabilities and responsibilities needed to direct and control their own units in order to achieve their specific goals, and respecting the goals of other units in the organization at the same time. Consequently, the major goals for the whole entity could be achieved and also the conflict of interests could be reduced if the contributions of each unit toward the overall goals of the organization were clarified in precise manner. So, the precise implementation of responsibility accounting will not materialize without adopting of organized decentralization. Furthermore, the organization must have an effective system to control and evaluate the performance of the subunits (responsibility centers) as recommended by Hilton (2000).

Finally, effective implementation requires also the presence of precisely prepared budgets in order to measure the performance of each division on the basis of actual and planned results as indicate by Odum (2000).

In order to specify responsibility centers and to prepare their budgets more effectively, participation is needed from all levels of management. Therefore, the prospective relationship between the centers should be determined and any potential obstacles must be managed properly. Consequently, the contribution of each unit toward overall organization goals is cleared and the varieties of participant's skills will utilized in organizational manner.

The study conducted to disclose the methods that are used to evaluate the financial and operational performance in the Jordanian health care institutions and its relation with responsibility accounting system. Moreover, the study tried to identify the problems that abstain of full implementation of responsibility accounting system in evaluation and decision making process. 


\section{Ml Macrothink}

Journal of Management Research

ISSN 1941-899X

2013, Vol. 5, No. 1

The importance of selecting medical institutions was mainly came from the fact that the nature of their work requires a division of entity into responsibility centers or units according to the diversity and specificity of work of each unit .For example, there are emergency departments, radiology, pharmacy, operations, and daily clinics, all these units separately operated and is connected with the other units at the same time. So there must be orderly and accurate measure to assess the financial and operational performance for each unit and in isolation from the other units and to reduce the possibility for evaluate the performance of any unit at the expense of other units' performance.

\section{Literature Review}

The core dilemma in every economy is the scarcity of resources, therefore, the appropriate allocation of resources will lead to minimize the exhaustion of these resources and minimize the cost production, and this means that production efficiency will be maximized and also profits (Friebel \& Raith, 2009). Responsibility accounting is a cost effective system, furthermore this system disclose management efficiency and provide information for decision making process as mentioned by Atiah( 1988) and for the assessment of the operational and financial performance; this evaluations includes the objective and subjective assessments of the performance of both individuals and subunits or organization as a whole (Jensen \& William,1988. the budgeting system is regarded as traditional controlling and managing system (Bergstrand \& Olve, 1996), also this system is used for planning and coordinating of next year activities (Arwidi,1991). Budgeting aims to assign responsibility for future performance evaluation (Libby \&Lindsay, 2003). The implementation of responsibility accounting is important in organizations either nonprofit government agencies (Khasharmeh \&Alomary, 2002, Almoneef, 1993), or profit private sector firms as indicated by Maidh (2003). As a nonprofit institution its main goal is the pursuit of social public welfare activities, the provision of social services to the public rather than to maximize the efficiency out their operations (Schiff \& Weisberg, 1991), nevertheless, its performance should be evaluated scientifically, and the variation between the actual and planned goals should be assessed properly, and the assessment results should be used to diagnose and identify the problems that may prevent improving their services, and finally to make any adjustments to achieve an appropriate organizational structure as assured by Duan(2010).

The following are some detailed literature concerning in responsibility accounting field in the Middle East countries:

\section{(Maidh Ibrahim, 2003) study}

This study tried to expand the knowledge about implementation of responsibility accounting system in Jordanian industrial companies.

A questionnaire has been prepared to acquire information relating to the study sample, which consisted of (89) industrial corporations that are listed in Amman exchange market for the year 2001. The study hypotheses were prepared depending on the main ingredients of responsibility accounting system, like organization's structure and budgets, where the descriptive statistical approach was used to analyze the research hypotheses. 


\section{Macrothink}

The study concluded that two third of the investigated sample do not adopt responsibility accounting system, while the implementation were imperfect in two third of the companies who adopted this system. Second, the responsibility centers are specified according to the organizational structures but the companies did not obligated by it. Third, the budgeting methods were not adopted by all companies, Furthermore; there were no specific systems for incentives and compensations with respect to the target sample.

\section{(Khasharmeh Hussein and Alomary Ahmed, 2002) study}

This study was prepared to obtain qualitative information to assess the possibility of implementing responsibility accounting system in Jordanian governmental agencies, to accomplish this goal a questionnaire were designed that is directed to the study sample which consisted of accountants, internal auditors and managers working in governmental agencies. The researchers used the descriptive statistics methods to analyze the results of this study.

The main results of this study showed that the majority of respondents expressed their desire to implement the responsibility accounting system in the governmental agencies for its advantages, Because of their positive impact on the performance of government agencies in their view. And these approvals were more in responses of higher educational degrees holders.

the study concluded at the importance of implementation of responsibility accounting system in governmental agencies due to its role in controlling the financial and legal performance of these units, furthermore, it is vital providing all the forms of support in order to implement this system.

\section{(Atiah, Suleiman 1988) study}

The study aimed to identify the bases and steps to implement responsibility accounting, the role of budgets in responsibility accounting system, and how to measure the performance of the responsibility centers. The researcher depended on case study method and qualitative research techniques to accomplish the study objectives.

The study concluded that the adoption of responsibility accounting system will benefit the organizations by improving the performance assessment methods and improve the system of compensation. Moreover, The study accentuated the importance of responsibility centers role in achieving the organizations main goals, Through participation in setting these goals, this participation could be more efficient when there is a precise definition of authority granted to each unit, as well as responsibilities assigned to it, this will just be achieved through adoption of rigorous reporting system. Under this system should identify the variables that may be under the control of centers mangers and which is not controllable. And this will enable us to access to the equation (responsibility $=$ Authority). The study recommended that this system should be adopted by top management, taking into account the trade -off between cost and benefit of this adoption

\section{(Alsayed and Mlaah, 1987) study}

The study aimed to display the role of responsibility accounting system in increasing production efficiency through its effectiveness on controlling the costs and securing the 
performance standards. And also its role in linking the performance with its related centers, and this leads to decrease costs and increase the quality of production. The researcher adopted the qualitative research method to attain the goals of this study. The study concluded that responsibility accounting system may help to set standards to measure and evaluate the production efficiency for each component of the production factors and thus any deviations could be early detected, and assigning the responsibility for these deviations would be more easily. So, the ability to handle any errors which caused by these deviations, could be enhanced.

This study aims to assess the government accounting information system in Saudi Arabia in terms of its efficiency in the evaluation of performance at partial and general level. Accordingly, the study tried to identify the possibilities for adopting alternative system for performance evaluation, which depends on responsibility accounting system. In order to achieve these goals, the researcher has conducted in-depth study on state budget in terms of preparation procedures, and also studying the managerial and accounting information systems in Saudi Arabia. The study concluded that the governmental accounting system in Saudi Arabia only depended on the evaluation of the overall performance of government agencies and that this assessment relied primarily on the extent of compliance with the financial and legal aspects only .and it also ignored the achievement of managerial supervision .The study recommended to the importance of utilization the concept of cost and managerial accounting system in Saudi government agencies and to the importance of securing the fundamentals resources for implementation.

\section{Research Methodology}

In order to accomplish the study objectives, a questionnaire has been prepared to collect the primary data from working persons in managerial accounting field in health care organizations in the north of Jordan. The questionnaire consist three partitions; the first part investigates the characteristics of the responders. While the second part looks at the characteristics of the study sample at the individual and organization level. Part III consists of the phrases that are supposed to measure all study hypotheses.

The study population includes all institutions operating in health care sector in the region of Irbid municipality (non government organizations and private sector institutions).

The questionnaire had been distributed by the researcher himself on the basis three copies for each institution. Where, the questionnaire will be directed to the financial manager, chief of the accounting department, and chief of the managerial accounting department if any. The sample consisted of eight institutions represent the study population. The distributed Questionnaires were collected, and the response percentage was 100\%.

\section{Attributes of the Study Sample}

I. Five members of the sample were for - profit institutions and the remainders were nonprofit associations. 
II. Four members of the sample provide comprehensive health care services; two of them were nonprofit organizations. The remainders were specialized in providing only one health care service one of them was nonprofit organization.

III. $81 \%$ of the respondents were males, and $50 \%$ of them were more than 36 years old holding the first university degree.

IV. $63 \%$ of the respondents were more than 11 years experience.

V. $63 \%$ of respondents were occupied financial manager job, 32\% were chief accountant position and only $7 \%$ was managerial accountant.

\section{Research Hypotheses}

For the purpose analyzing the data collected through the questionnaire, the study depended on descriptive statistics methods (mean, standard deviation, and significance level $\alpha=0.005^{*}$ ). The Quintet Likert scale was used in order to determine the degree of agreement about questionnaire's statements. The respondents were asked to express their opinions about each statement in the questionnaire through assigning a signal (x) for each degree of approval degrees that encompassed of phrases; strongly agree, agree, natural, reject, and strongly reject. The mean (arithmetic average) of these responses will be to judged as follows:

\begin{tabular}{|l|l|l|}
\hline \multicolumn{2}{|l|}{ Mean range } & \multirow{2}{*}{ Hypothesis judgment } \\
\hline From & To & Rejection \\
\hline 1.0 & 2.499 & Weak approval \\
\hline 2.5 & 3.499 & Strong approval \\
\hline 3.5 & 5.000 & \\
\hline
\end{tabular}

\section{Hypotheses Testing}

The study includes nine hypotheses; these hypotheses were tied by one or more questionnaire statement. The first three hypotheses were designed to measure the extent of implementing responsibility accounting system in the target sample. The fourth and the fifth hypotheses pursues to identify how the financial performance is evaluated, and to what extent this evaluation is related to responsibility accounting principles. The sixth and seventh hypotheses were prepared to uncover the factors that may affect to adopt this system if any. As for the last two hypotheses, the aim of them is to explore the ability and willingness of management at all levels for adoption of this type of accounting systems in future.

\section{H1: There is an organizational structure where every managerial level is distinctly defined.}

This hypothesis was tested through the first questionnaire's statement; the organization structure is well specified. This hypothesis was approved (80\% strong approval, the mean of responses 4.00 , standard deviation 1.0954 , and $\alpha=0.00433 *$ significance level). And this means that there is a consensus by the study sample about the existence of a strict organization structure in their institutions. 


\section{Macrothink}

Journal of Management Research

ISSN 1941-899X

2013, Vol. 5, No. 1

H2: There is a definite responsibility centers in each organization which are related with the organization structure.

The hypothesis is tested by the questionnaire's second statement; the responsibility centers are sub-divided according to the organization structure. This hypothesis was approved $(77.5 \%$ strong approval, mean of responses 3.875, standard deviation 1.0247, and $\alpha=0.0002 *$ significance level). This result can be interpreted on the basis of it's kind of commitment to the rules of procedure of the institutions regardless of whether this adoption is a form of adoption of responsibility accounting principles.

\section{H3: There is an organized budgets preparation for each center in the organization.}

The hypothesis is tested by the questionnaire's third statement; Budgets are prepared for each responsibility center in a systematic and organized manner. This hypothesis was weakly approved (58.75\% approval, mean of responses 2.9375, standard deviation 1.3, and $\alpha=0.2997 *$ significance level). It should not be inferred from these results that there is an organized budgets preparation even if there is weak approval.

H4: The evaluation of the financial performance in each center depends on the center's effectiveness in achieving the budgeted goals.

This hypothesis is tested by the questionnaire's fourth statement; the performance evaluation of each responsibility center is done according to its own budget. This hypothesis was approved (60\% approval, the mean of responses 3.00, standard deviation 1.3166, and $\alpha=0.33297$ significance level). It should be noted also that there is harmony in responses of this hypothesis and the responses of previous hypothesis, which stated a weak approval concerning the presence of organized budget for each responsibility center, since the absence of an organized budgeting system would not logically lead to adopt this system for performance evaluation. And this may enhance the sample's creditability.

H5: There is a periodical reports used to evaluate the performance of each center.

This hypothesis is tested by the questionnaire's fifth statement; reports are prepared regarding the performance of each responsibility center. This hypothesis is weakly approved (65\% approval, the mean of responses 3.25, standard deviation 1.1255, and $\alpha=0.002043 *$ significance level).

H6: The type of the organization and its main activity effects the implementation of responsibility accounting system.

This hypothesis is tested by the first twelve statements 
1. The organization structure is well specified

2. The responsibility centers are sub-divided according to the organization structure

3. Budgets are prepared for each responsibility center in a systematic and organized manner

4. the performance evaluation of each responsibility center is done according to its own budget

5. reports are prepared to evaluate each responsibility center's performance

6. There is a delegation of responsibility from top to lower management levels in a systematic way

7. the top management is informed and aware of the benefits of responsibility accounting

8. The lower management levels are informed and aware of the benefits of responsibility accounting

9. The evaluation and compensation system is not correlated with organization performance as whole

10. Responsibility center managers have the ability to take decisions in their divisions and that may affect other responsibility centers in the organization.

11. There is a coordination between the organization centers in the same management level

12. There is a coordination between the organization centers and the top management

The results showed that the respondents of comprehensive health institutions have strongly agreed on the adoption of their institutions responsibility accounting principles, even if partially, with (mean 3.56) standard deviation of 0.8773 , and ( $\left.\alpha=0.00456^{*}\right)$ significance level. While the approval were weak in the comprehensive health institutions, (mean 3.23) and standard deviation of 1.0431, and significance level $\left(\alpha=0.0017^{*}\right)$.

In addition, there were weak approval regarding the implementation of responsibility accounting system in profit and non- profit institutions alike (means 3.428, 3.418 respectively) and (standard deviation of 1.0431, 1.578 and significance level $(\alpha=0.2215,0.009 *)$, and this also reinforce the sample credibility with respect to the previous hypotheses.

\section{H7: the decision making process in the organization is unrelated to responsibility} accounting system. This hypothesis is tested by the following statements:

13. The decisions which are belong to each center are taken by top management upon its" vision

14. Decisions that relate to each responsibility center are taken after consultation or approval of top management.

15. Decisions that relate to each responsibility center are taken as a response to external influences (like competitors)

16. Decision-making process is delegated to certain individuals, regardless of their location in the organizational structure.

Only profit institutions showed that they are relying on other techniques in decision- making in the absence of responsibility accounting (mean 3.5), standard deviation of 0.3093, and significance level $(\alpha=0.00401)$. While, the nonprofit institutions expressed a weak approval or disagreement concerning this hypothesis (mean 2.665, standard deviation of 0.3093, and significance level $\alpha=0.0007$ ), and this may be regarded as inconsistency with previous results about their approval of responsibility accounting implementation. With respect to comprehensive health institutions and specialized, there was disagreement or a weak approval on this hypothesis. (Mean: 3.305, 2.895, standard deviation: 0.19, 0.712, and significance level: $\alpha=0.000$, $(\alpha=0.1103)$. 
H8: There is a tendency and willingness of the top managements to implement the responsibility accounting system.

This hypothesis is measured by the following statements:

6. There is a delegation of responsibility from top to lower management levels in a systematic way

7. the top management is informed and aware of the benefits of responsibility accounting

9. The evaluation and compensation system is not correlated with organization performance as whole

11. There is a coordination between the organization centers in the same management lievel

The sample strongly agrees that there is tendency and willingness by top managements to implement the responsibility accounting system (mean 3.625, standard deviation 0.813, 0.19, and significance level $\alpha=0.0019$ ), But this result can be interpreted differently through top management courtesy by respondents.

\section{H9: There is a tendency and willingness of the lower managements levels to implement responsibility accounting system.}

8. The lower management levels are informed and aware of the benefits of responsibility accounting

10. Responsibility center managers have the ability to take decisions in their divisions" and that may affect other responsibility centers in the organization.

12. There is a coordination between the organization centers and the top management

There is a weak approval about the tendency and willingness of the lower management levels to implement responsibility accounting system (mean 3.3125, standard deviation 0.963 , and significance level $\alpha=0.0694$ ) so this hypothesis were rejected, this rejection could be interpreted in two different ways, it may inferred as an approval or rejection in some institutions and not all.

\section{Results}

1- There was a consensus within the study sample on the presence of a definite organizational structure in their organizations, and they also agree that these organizations were divided to responsibility centers in accordance with the organizational structure.

2- There was a consensus about the using of periodical reports to evaluate the performance for each center. But there was no consensus about the adoption of performance evaluation techniques that are based mainly on the effectiveness of these centers in achieving the goals that were set for them in their own budgets. Moreover, the presence of an organized budget for each center was a matter of dispute within the study sample

3- It may inferred from the analysis of the study hypotheses that the comprehensive medical institutions and non-profit organizations adopt the responsibility accounting principles partially, while this was not appeared in the specialized medical institutions and for-profit institutions.

4- There were approval in the for-profit institutions that they depend on methods to evaluate their performance which are not related with responsibility accounting principles, and a lesser 


\section{Macrothink Institute ${ }^{\mathrm{TM}}$}

degree of approval in the nonprofit and specialized medical institutions, while the comprehensive medical institutions were opposed this assumption.

5- The sample of the study confirmed that there is ability and willingness by top management to adopt responsibility accounting system, this ability and willingness was less at the lower levels of management.

\section{Conclusion}

The study concluded that the medical institutions in northern Jordan are partially adopting the fundamentals of responsibility accounting system in the evaluation of its performance. And this adoption was informal.

This conclusion is supported by:

1- The presence of definite organizational structures, where the centers (cost and profit centers) were divided according to those structures. (And it can also be considered as a kind of commitment to the rules of procedure for these institutions).

2- The absence of systematic preparation for budgets to each responsibility center. And this weakens the ability of the institution in controlling the operational and financial performance to its divisions.

3- the tendency toward decentralization(delegation of authority) in these institutions were weak, where there was significant influence by top management in the process of decision making and performance evaluation in centers and at the entire organization level . Therefore, the efficiency of the reporting system in the process of assessing performance will be questionable.

\section{References}

Almoneef Abdullah Ali. (1993). The study of the ability of implementation the responsibility accounting system in the Saudi Arabia kingdom governmental agencies. Public administration review, 77, 113-147

Alsaid, Mohamed, \& Almalah Nisar. (1987). The role of the responsibility accounting system in increasing the production efficiency. Alrafidai development, 20, 319-345.

Atiah, Suleiman. (1988).The role of the responsibility accounting system in measuring the efficiency and effectiveness of the management. Public administration review, 57, 57-92.

Garrison, R.H. (2000). Management Accounting: Concept for Planning Control and Decision-Making. 5e. ISBN-13: 9780256058338. McGraw-Hill.

Gordon L. A. (2004). LSC Managerial accounting: Concepts and Empirical Evidence plus Supplement. 6e. ISBN- 139780073270685. McGraw-Hill

Guido Friebel1, \& Michael Raith. (2007). Resource Allocation and Firm Scope. Simon School Working Paper No. FR 06-16. 
Haiyan Duan. (2010). A Survey of Non-profit Organizations Evaluation Methods. Asian Social Science, 6(8), 30-41.

Hilton, R.W. (2010). Managerial accounting. 9e. ISBN-10: 0078110912 .McGraw-Hill.

Khasharmeh, Hussein, \& Alomary Ahmed. (2004). Measuring the ability of implanting the responsibility accounting system in the government agencies in Jordan. Yarmouk research review, 259-287.

Maidh Omer. (2003). The responsibility accounting system in Jordanian industrial corporations, actual and expectations. Damascus University Reviews, 19(2), 317-364.

Malodia G. L. (2011). Responsibility accounting (a case study) Lachoo Management Journal, 2(1), IX: XVIII

Michael C. Jensen, \& William H. Meckling. (1988). Divisional Performance Measurement. http://papers.ssrn.com/abstract $=94109$

Moore M. H. (2003). The Public Value Scorecard: A Rejoinder and an Alternative to 'Strategic Performance Measurement and Management in Non-Profit Organizations' by Robert Kaplan. Hauser Center for Nonprofit Organizations Working Paper No. 18. http://ssrn.com/abstract $=402880$

Odum, A. N. (2006). Responsibility accounting: A Tool for Managerial Control in the Public Sector. Journal of Business Studies and Research, 3(1), 204-219

Sarkar, J.B., \& Yeshmin, F. (2005). Application of Responsibility Accounting. Bangladesh Perspective (The Cost and Management), 33(6), 82-88.

Williams, J, B. (1938). The theory of investment value. Cambridge Massachusetts: Harvard university press. 